Institute for Evidence-Based Healthcare, Bond University, Australia

2 Cochrane Sustainable Healthcare, Sweden

3 Patient Advisors Network, Canada

4 Department for Emergency Medicine, Cumming School of Medicine, University of Calgary, Canada

5 Department of Family Medicine and Emergency Medicine, Laval University, Canada

Correspondence to: R Moynihan rmoyniha@bond.edu.au

Cite this as: BMJ2020;370:m2752 http://dx.doi.org/10.1136/bmj.m2752 Published: 14 July 2020

\section{Covid-19: an opportunity to reduce unnecessary healthcare}

\author{
Recovering health systems can prioritise genuine need
}

\author{
Ray Moynihan, ${ }^{1}$ Minna Johansson, ${ }^{2}$ Alies Maybee, ${ }^{3}$ Eddy Lang, ${ }^{4}$ France Légaré ${ }^{5}$
}

Alongside the human suffering, covid-19 is also threatening the sustainability of health systems. The continuing costs of the pandemic combined with the impending financial crisis will inevitably mean having to do more with less. The tragedy of the pandemic has paradoxically produced an opportunity to tackle the increasingly recognised challenge of "too much medicine" safely and fairly-to help improve both sustainability and equity in healthcare. This well described problem of unnecessary tests, diagnoses, and treatments causes harm and wastes resources that could be better used for those in genuine need. ${ }^{12}$

The case for tackling too much medicine was clear before covid-19. ${ }^{1-7}$ Reports from the US and the Organisation for Economic Cooperation and Development suggest that at least a fifth of routine healthcare spending may be wasted, including on overdiagnosis and overuse. ${ }^{34}$ In Canada, patients receive more than a million potentially unnecessary tests and treatments each year, according to recent estimates. ${ }^{5}$ The threats from overuse and overdiagnosis may be even more serious in low and middle income countries. ${ }^{6}$

Every health system experiences this problem, ${ }^{7}$ and some are starting to address it. The UK's biggest public funding body is calling for research proposals to reduce overtreatment, ${ }^{8}$ while in Australia, one health system is investigating how to enhance the value of care and the systems' sustainability, in the wake of covid-19. ${ }^{9}$

More immediately, health system managers are facing urgent questions about how to deal with big backlogs in elective surgery and other procedures that have been postponed in recent months. Two year waiting lists for some procedures are now a possibility in parts of Canada, for example. This has forced a renewed focus on reducing inappropriate care-such as magnetic resonance imaging for uncomplicated osteoarthritis ${ }^{10}$ - to enable much more rapid care for those on waiting lists who are in genuine need.

As a group of doctors from the Quebec College of Family Physicians has argued, the crisis caused by the pandemic requires health systems to prioritise interventions "that have demonstrated effectiveness and concrete benefits for patients." ${ }^{11}$ Mounting evidence of overuse of medical interventions, ${ }^{1}$ and campaigns such as Choosing Wisely that aim to avoid overuse, ${ }^{10}$ are more relevant than ever.

\section{Natural experiment}

The use of healthcare services has fallen steeply during the pandemic, ${ }^{12-14}$ offering a rare opportunity to analyse a natural experiment in less medical care. In the US, the number of visits to hospitals, emergency departments, and family doctors almost halved at the height of the pandemic. ${ }^{12-14}$ Clearly, many people were unable to access needed care, including routine vaccinations, ${ }^{15}$ and lives have been lost as a result-for example, from heart disease. ${ }^{13}$ Others, however, have avoided unnecessary tests, diagnoses, and treatments that would have caused them more harm than good.

Although recent analyses suggest that use of healthcare is bouncing back, there are still large "cumulative deficits" of missed care over recent months. ${ }^{14}$ One of the biggest and most sustained falls has been in visits to doctors involving young children. ${ }^{14}$ We know that children experience overdiagnosis and overtreatment-for example, through an inappropriate label of attention deficit/hyperactivity disorder or gastroesophageal reflux ${ }^{16}$-so some of those children who missed visits may have avoided an unnecessary label, invasive diagnostic procedure, or the complications of inappropriate treatment. At the same time adults who have missed an annual health check-up may have avoided an intervention of little or no benefit that carries a risk of harm from unnecessary diagnoses. ${ }^{17}$

Analysing the effects of this natural experiment in reduced healthcare will be as challenging as it is necessary. International collaborations are required between researchers, health system managers, clinicians, and patient and public representatives. Initially, data can be collated at local, regional, and national levels to determine how rates of common tests, diagnoses, and treatments have changed. Those lists could then be mapped against lists of known low value care, including overused interventions and overdiagnosed diseases. ${ }^{1}$

More focused rigorous studies can then investigate the effects of reduced healthcare use on patient outcomes and costs. Understanding the extent of increased mortality and morbidity arising from missed care is critical, but so too is identifying and quantifying any benefits. Qualitative analysis of people's motivations for, and experiences of, avoiding care will also be important.

This pandemic has provoked the best of human compassion and solidarity, but those who manage our health systems still face extraordinary challenges responding to covid-19 and preparing for the second wave. Looking beyond the crisis, our collective learning about the effects of the large falls in healthcare use can help inform and intensify efforts to reduce unnecessary care. This in turn can prevent avoidable harm to patients, enhance healthcare equity, and improve the sustainability of health systems everywhere. 
Competing interests: We have read and understood BMJ policy on declaration of interests. and have no relevant interests to declare. All authors write as individuals rather than as representatives of the organisations they work for.

Provenance and peer review: Commissioned; not externally peer reviewed.

1 Morgan DJ, Dhruva SS, Coon ER, Wright SM, Korenstein D. 2019 update on medical overuse: a review. JAMA Intern Med 2019;179:1568-74.

doi: 10.1001/jamainternmed.2019.3842 pmid: 31498374

2 Glasziou P, Moynihan R, Richards T, Godlee F. Too much medicine; too little care. BMJ 2013;347:f4247. doi: 10.1136/bmj.f4247 pmid: 23820022

3 Berwick DM, Hackbarth AD. Eliminating waste in US health care. JAMA 2012;307:1513-6. doi: 10.1001/jama.2012.362 pmid: 22419800

4 OECD. Tackling wasteful spending on health. 2017. doi: 10.1787/9789264266414-en

5 Canadian Institute for Healthcare Information. Unnecessary care in Canada: infographic. 2017. https://www.cihi.ca/en/unnecessary-care-in-canada-infographic

6 Pathirana T, Wang Yu M, Martiny F, etal. 8 Drivers and potential solutions for overdiagnosis: perspectives from the low and middle income countries. BMJ Evidence-Based Medicine 2019;24(suppl 2):A6-7. doi: 10.1136/bmjebm-2019-POD.13

7 Laragh Gollogly: official welcome. Preventing Overdiagnosis International Scientific Conference, Sydney, 5-7 Dec 2019. https://www.armchairmedical.tv/media/Official+Welcome+Fiona+Godlee+BMJ+\%26+Laragh+Gollogy+WHO/0_lt786rva/146828052

8 National Institute for Health Research. Reducing overtreatment. 2020. https://www.nihr.ac.uk/documents/2033-reducing-overtreatment/24473

9 Queensland Health. Reform planning group. https://www.health.qld.gov.au/system-governance/strategic-direction/reform-planning-group

10 Choosing Wisely Canada. Five new orthopaedic recommendations released. 2018 https://choosingwiselycanada.org/perspective/five-new-orthopaedic-recommendations-released/

11 Breault P, Theriault G, Wittmer R, et al. Et si la COVID-19 vous avait sauvé(e)? Le Devoir 2020 Jun 15. https://www.ledevoir.com/opinion/idees/580791/et-si-la-covid-19-vous-avait-sauve-e

12 Hartnett KP, Kite-Powell A, DeVies J, etalNational Syndromic Surveillance Program Community of Practice. Impact of covid-19 pandemic on emergency department visits - United States, January 1, 2019-May 30, 2020. MMWR Morb Mortal Wkly Rep 2020;69:699-704. doi: 10.15585/mmwr.mm6923e1 pmid: 32525856

13 Baum A, Schwartz MD. Admissions to Veterans Affairs hospitals for emergency conditions during the covid-19 pandemic. JAMA 2020. doi: 10.1001/jama.2020.9972 pmid: 32501493

14 Mehrotra A, Chernew M, Linetsky D, et al. The impact of the covid-19 pandemic on outpatient visits: practices are adapting to the new normal. Commonwealth Fund, 2020.

https://www.commonwealthfund.org/publications/2020/jun/impact-covid-19-pandemic-outpatientvisits-practices-adapting-new-normal

15 Saxena S, Skirrow H, Bedford H. Routine vaccination during covid-19 pandemic response. BMJ 2020;369:m2392. doi: 10.1136/bmj.m2392 pmid: 32546575

16 Coon ER, Quinonez RA, Moyer VA, Schroeder AR. Overdiagnosis: how our compulsion for diagnosis may be harming children. Pediatrics 2014;134:1013-23. doi: 10.1542/peds.2014-1778 pmid: 25287462

17 Krogsbøll LT, Jørgensen KJ, Gøtzsche PC. General health checks in adults for reducing morbidity and mortality from disease. Cochrane Database Syst Rev 2019;1: doi: 10.1002/14651858.CD009009.pub3 pmid: 30699470

This article is made freely available for use in accordance with BMJ's website terms and conditions for the duration of the covid-19 pandemic or until otherwise determined by BMJ. You may use, download and print the article for any lawful, non-commercial purpose (including text and data mining) provided that all copyright notices and trade marks are retained. 